\title{
ASYMPTOTIC EXPANSION OF THE ARITHMETIC-GEOMETRIC MEAN AND RELATED INEQUALITIES
}

\author{
TOMislav Burić AND NEven ElEZOVIĆ
}

Abstract. Asymptotic expansion of the arithmetic-geometric mean is obtained and it is used to analyze inequalities and relations between arithmetic-geometric mean and other classical means.

Mathematics subject classification (2010): 26E60, 41A60.

Keywords and phrases: Arithmetic-geometric mean, asymptotic expansions, asymptotic inequalities.

\section{REFERENCES}

[1] M. Abramowitz And I. A. Stegun (Eds), Handbook of Mathematical Functions with Formulas, Graphs, and Mathematical Tables, National Bureau of Standards, Applied Mathematics Series 55, 9th printing, Washington, 1970.

[2] G. E. Andrews, R. A. Askey, And R. Roy, Special Functions, Cambridge University Press, Cambridge, 1999.

[3] P. BRACKen, An arithmetic-geometric mean inequality, Expo. Math., 19 (2001), 273-279.

[4] P. S. Bullen, Averages still on the move, Math. Mag., 63 (1990), 250-255.

[5] P. S. Bullen, Handbook of Means and Their Inequalities, Kluwer Academic Publisher, Dordrecht/Boston/London, 2003.

[6] P. S. Bullen, D. S. Mitrinović And P. M. Vasić, Means and theirs inequalities, D Reidel, Dordrecht, 1988.

[7] T. Burić, N. Elezović, Bernoulli polynomials and asymptotic expansions of the quotient of gamma functions, J. Comput. Appl. Math., 235, 11 (2011), 3315-3331.

[8] T. Burić, N. Elezović, New asymptotic expansions of the gamma function and improvements of Stirling's type formulas, J. Comput. Anal. Appl., 13, 4 (2011), 785-795.

[9] T. Burić, N. ElEZović, New asymptotic expansions of the quotient of gamma functions, Integral Transforms Spec. Funct., 23 (2012), 355-368.

[10] T. BURIĆ, N. ElEZoviĆ, Approximations of the Euler-Mascheroni constant and harmonic numbers, Appl. Math. Comput., 222 (2013), 604-611.

[11] T. Burić, N. Elezović, Asymptotic expansions of the binomial coefficients, J. Appl. Math. Comput., 46 (2014), 135-145.

[12] C.-P. ChEn, N. Elezović AND L. VuKŠIĆ, Asymptotic formulae associated with the Wallis power function and digamma function, J. Class. Anal. 2 (2013), 151-166.

[13] N. Elezović, Asymptotic inequalities and comparison of classical means, J. Math. Inequal. 9, 1 (2015), 177-196.

[14] N. ELEZović, Asymptotic expansions of gamma and related functions, binomial coefficients, inequalities and means, J. Math. Inequal 9, 4 (2015), 1001-1054.

[15] N. ElezoviĆ AND J. PeČARIĆ, Differential and integral $f$-means and applications to digamma function, Math. Inequal. Appl. 3 (2000), 189-196

[16] N. ElezoviĆ, L. VUKŠIĆ, Asymptotic expansions of integral means and applications to the ratio of gamma functions, Appl. Math. Comput. 235 (2014), 187-200.

[17] N. Elezović AND L. VuKŠIĆ, Asymptotic expansions of bivariate classical means and related inequalities, J. Math. Inequal. 8 (2014), 707-724.

[18] N. Elezović AND L. VUKŠIć, Asymptotic expansions and comparison of bivariate parameter means, Math. Inequal. Appl. 17 (2014) 1225-1244. 
[19] F. QI, A. SOFO, An alternative and united proof of a double inequality for bounding the arithmeticgeometric mean, U.P.B. Sci. Bull. 71 (2009) 69-76.

[20] M. K. Vamanamurthy and M. Vuorinen, Inequalities for means, J. Math. Anal. Appl, 183 (1994), 155-166. 